\title{
A PESQUISA EM EDUCAÇÃO: APROXIMAÇÕES INICIAIS
}

\author{
INVESTIGACIÓN EN EDUCACIÓN: PRIMERAS APROXIMACIONES
}

\author{
RESEARCH IN EDUCATION: INITIAL APPROACHES
}

\author{
Mariana Luzia Corrêa THESING ${ }^{1}$ \\ Fabiane Adela Tonetto COSTAS ${ }^{2}$
}

RESUMO: A atividade de pesquisa, desde a antiguidade, está voltada à compreensão do mundo, ao desejo de desvendar/desvelar o que está oculto. Está relacionada ao indagar, ao questionar o que está dado, ao que parece natural. Este texto, a partir dessas premissas, tem como objetivo discutir a atividade de pesquisa em educação tendo em vista seu caráter político e pluridisciplinar. A partir de uma pesquisa bibliográfica (Marconi; Lakatos, 2003), propõe a discussão acerca dos desafios relacionados à natureza das abordagens metodológicas e à prática dos pesquisadores na atividade de pesquisa no campo educacional. Como resultados, indica a complementaridade das abordagens qualitativa e quantitativa como um caminho possível para abranger a máxima compreensão da realidade estudada nas pesquisas em educação e discute alguns desafios característicos das pesquisas em educação e das abordagens qualitativas.

PALAVRAS-CHAVE: Pesquisa em educação. Pesquisa qualitativa. Abordagens metodológicas.

RESUMEN: La actividad de investigación, desde la antigüedad, se centra en la comprensión del mundo, el deseo de descubrir/revelar lo que está oculto. Se relaciona a investigar, cuestionar lo que se da, parece natural. Este texto, a partir de estas premisas, tiene como objetivo discutir la actividad de investigación en la educación en vista de su carácter político y multidisciplinaria. A partir de una búsqueda en la literatura (Marconi; Lakatos, 2003), propone una discusión sobre los desafíos relacionados con la naturaleza de los enfoques metodológicos y la práctica de los investigadores de la actividad investigadora en el campo de la educación. Como resultado de ello, indica la complementariedad de los enfoques cualitativos y cuantitativos como una posible manera de cubrir la máxima comprensión de la realidad estudiada en investigaciones sobre la educación y discute algunos de los retos típicos de la investigación en la educación y los enfoques cualitativos.

PALAVRAS CLAVE: Investigación educativa. La investigación cualitativa. Enfoques metodológicos.

1 UFSM - Santa Maria - Brasil. Doutoranda do Programa de Pós-Graduação em Educação da Universidade Federal de Santa Maria (UFSM). E-mail: marluzcor@gmail.com

${ }^{2}$ UFSM - Santa Maria - Brasil. Doutora em Educação (UFRGS). Professora Associada do Departamento de Fundamentos da Educação e do Programa de Pós-Graduação do Centro de Educação da Universidade Federal de Santa Maria (UFSM). E-mail: fabicostas@gmail.com 
ABSTRACT: The research activity, since antiquity, is directed to the understanding of the world, to the desire to unveil/unveil what is hidden. It is related to inquiring, questioning what is given, which seems natural. This text, based on these premises, aims to discuss the activity of research in education in view of its political and pluridisciplinary character. From a bibliographical research (Marconi; Lakatos, 2003), it proposes the discussion about the challenges related to the nature of the methodological approaches and to the practice of the researchers in the activity of research in the educational field. As a result, it indicates the complementarity of the qualitative and quantitative approaches as a possible way to encompass the maximum comprehension of the reality studied in the researches in education and discusses some characteristic challenges of the researches in education and of the qualitative approaches.

KEYWORDS: Research in education. Qualitative research. Approaches.

\section{Introdução}

Pesquisar é uma atividade voltada à compreensão do mundo, ao desejo de desvendar/desvelar o que está oculto. Está relacionada ao indagar, ao questionar o que está dado, ao que parece natural. Pesquisar é uma atividade que exige estranhamento, questionamento, inconformidade ao posto como correto, como ordem; tem como objetivo a busca do conhecimento do que se esconde no cotidiano. Pesquisar, então, está associado à necessidade de conhecer, de procurar possíveis respostas a hipóteses pensadas a priori pelo pesquisador - estas que podem ser refutadas tendo em vista o que dizem àquelas, dentro de determinado campo de possibilidades de análise.

A atividade de pesquisa, com seu caráter político, não deve ser atividade exclusiva de alguns eleitos, em condições assépticas, longe do cotidiano. A atividade de pesquisa, assim como a atividade de ensino, é um ato político que se fundamenta em pressupostos de liberdade ou de dominação no campo científico. Assim, dependendo da escolha política e ideológica do pesquisador, seus estudos e investigações contribuirão para a transformação ou para a manutenção da realidade social.

A pesquisa no campo da Educação tem apresentado uma série de investigações acerca de diferenciados temas que discutem o processo educacional a partir de distintas perspectivas e análises. A atividade investigativa está alicerçada na busca pela compreensão dos diferentes objetos a ela relacionados, tendo em vista a produção do conhecimento que contribua com a transformação de seus processos. A multiplicidade de temas e objetos em estudo convergem na busca por compreender os processos formativos do professor, nas diferentes experiências que esse vivencia, tanto nos 
espaços escolares, como profissional em exercício, quanto nas escolas formadoras, em seus processos de formar-se professor.

Sem desvincular a pesquisa à sua função social, que é a construção do conhecimento, como atividade rigorosa e intencional, a prática de pesquisar, por ser um ato político, está aliada à prática cotidiana do professor que trabalha em contextos educativos. Isso porque a necessária relação entre pesquisa e ensino deve fundamentar a prática cotidiana do professor em atividade, para que suas aulas sejam pautadas pela construção do conhecimento e não pela sua mera reprodução. Logo, a pesquisa e o ensino - assim como as atividades de extensão - devem ser retroalimentadas numa constante revisão de suas bases epistemológicas.

Sobre a relação ensino e pesquisa, Paulo Freire (1996) afirma a relação intrínseca e necessária entre a atividade de pesquisa e a prática docente de ensinar, estas que, relacionadas, estão em busca do conhecimento, do senso comum à consciência filosófica (SAVIANI, 2009). Nesse sentido, Freire (1996) afirma que “[...] não há ensino sem pesquisa e pesquisa sem ensino. Esses que-fazeres se encontram um no corpo do outro. Enquanto ensino continuo buscando, reprocurando. Ensino porque busco, porque indaguei, porque indago e me indago" (FREIRE, 1996, p.29). Nessa discussão, Freire (1981) destaca os interesses subjacentes da pesquisa científica quando diz que

[...] considero importante, nessa altura de nossa conversa, insistir mais uma vez sobre o caráter político da atividade científica. A quem sirvo com minha ciência? Esta deve ser uma pergunta constante a ser feita por todos nós. E devemos ser coerentes com a nossa opção, exprimindo nossa coerência na nossa prática. (FREIRE, 1981, p. 34).

O presente texto, a partir de uma pesquisa bibliográfica (Marconi; Lakatos, 2003), tem o objetivo de discutir o processo de pesquisa, suas abordagens metodológicas e alguns elementos que se referem às suas possibilidades e desafios, tendo em vista o rigor científico necessário para a realização de "boas pesquisas" (ANDRÉ, 2005). Essas que são necessárias no campo educacional, aliadas a projetos investigativos com caráter libertador, que contribuam para a construção do conhecimento e para a compreensão e transformação da realidade humana, social e educacional.

\section{A atividade de pesquisa em educação: diálogos iniciais}


O estudo dos fenômenos educacionais, situado entre as Ciências Humanas e Sociais, sofreu as influências das evoluções nessas ciências. Como essas tinham interesse em adotar modelos de abordagem das áreas físicas e naturais, os estudos em educação foram organizados em uma perspectiva que acreditava no isolamento do fenômeno educacional e de suas possíveis variáveis, a fim de compreender as influências dessas sobre aquele (LÜDKE; ANDRÉ, 2012). Grande parte dos problemas das pesquisas em educação é devido à tentativa de se ter como referência o modelo positivista das ciências naturais, este que é alheio às especificidades dos objetos de pesquisa das ciências humanas e sociais.

A perspectiva do Positivismo, na sua tentativa de mensurar dados para compreendê-los e padronizando-os para obter resultados considerados verdadeiros na construção do conhecimento, não serve aos propósitos das Ciências Humanas e Sociais. Isto porque foi se percebendo que os objetos de análise desse campo têm outra natureza, não são padronizáveis e mensuráveis, passíveis de isolamento em testes de laboratórios. Nesse sentido, novas formas de pensar a pesquisa sobre os fenômenos relacionados à educação exigiram do pesquisador em educação uma postura flexível e criativa para coletar e analisar os elementos de sua pesquisa. Surgem então as pesquisas qualitativas em educação que tinham/têm como propósito “[...] evitar o tecnicismo e o reducionismo lógico-formal nas investigações educacionais em favor da recuperação da subjetividade". (DEVECHI; TREVISAN, 2010, p.150).

Diante de uma série crescente de temas investigados, que se ampliam e diversificam, há, a partir da década de 80 , o surgimento de uma multiplicidade de enfoques e abordagens metodológicas no campo da pesquisa em educação. Para dar conta de compreender os múltiplos objetos de pesquisa, os enfoques passam a ser entendidos numa necessária dimensão multirreferencial e multi/inter/transdisciplinar, tendo em vista as contribuições da Psicologia, da Sociologia, da Antropologia, da História, da Linguística e da Filosofia (ANDRÉ, 2005). Nesse movimento, na busca por conhecer e interpretar os processos e contextos da área educacional, a abordagem qualitativa apresenta uma gama de tipologias metodológicas, que prometem a interpretação dos fenômenos e o rigor científico entendido como necessário.

Ganham força os estudos "qualitativos", que englobam um conjunto heterogêneo de métodos, de técnicas e de análises, que vão desde os estudos antropológicos e etnográficos, as pesquisas participantes, os estudos de caso até a pesquisa-ação e as análises de discurso, de narrativas, de histórias de vida. (ANDRÉ, 2005, p. 6). 
Há muitos questionamentos acerca da natureza e da validade das pesquisas qualitativas em educação em razão da premissa de que faltaria rigor científico nesse tipo de abordagem, que resultaria em processos investigativos com análises ametódicas e generalistas. Questiona-se o nível de cientificidade dessas pesquisas, estas apontadas como meras descritoras da realidade, sem o desenvolvimento de uma interpretação científica das realidades. De acordo com Devechi e Trevisan (2010) "[...] a contestação reside na desconfiança de que esse modelo investigativo estaria demonstrando dificuldades em ir além daquilo que seria uma mera interpretação imediatista da realidade, tornando-se mais descritora do óbvio do que investigadora científica" (p.149).

Essa crítica às pesquisas qualitativas pode, de acordo com os autores, estar relacionada a uma crise das próprias abordagens qualitativas, numa "decadência de sua história" ou ainda ser fruto de uma tendência positivista que acredita na construção da ciência a partir de dados objetivos. Para André (2013), o rigor metodológico nas abordagens qualitativas não se reduz à atribuição de nomes que designam os tipos de pesquisa desenvolvidos, mas está relacionada à organização do caminho investigativo, feita a partir da descrição clara e concisa a respeito das escolhas metodológicas feitas pelo pesquisador.

Isso sim é importante, porque revela a preocupação com o rigor científico do trabalho, ou seja: se foram ou não tomadas as devidas cautelas na escolha dos sujeitos, dos procedimentos de coleta e análise de dados, na elaboração e validação dos instrumentos, no tratamento dos dados. Revela ainda a ética do pesquisador, que ao expor seus pontos de vista dá oportunidade ao leitor de julgar suas atitudes e valores. (ANDRÉ, 2013, p. 96).

Com a proposição das pesquisas qualitativas em educação e a partir do entendimento da complementariedade dos métodos para o conhecimento global da realidade, surge a possibilidade da relação entre os métodos quantitativos e os qualitativos nas pesquisas. De acordo com Devechi e Trevisan (2010), os métodos quantitativos e os métodos qualitativos são complementares na compreensão dos fenômenos em educação. Ou seja, o pesquisador deve optar pela utilização das duas abordagens a fim de aproveitar as qualidades de cada uma delas para abranger a máxima compreensão da realidade estudada. De acordo com os autores, "[...] a pesquisa qualitativa não é contrária à pesquisa quantitativa, pois não se trata de posições antagônicas, mas desiguais e complementares” (DEVECHI; TREVISAN, 2010, p. 157). 
Nesse mesmo sentido, Goldenberg (2004) também defende a ideia da complementaridade entre as abordagens quantitativas e qualitativas na pesquisa em Ciências Sociais, por acreditar que as diferentes perspectivas podem auxiliar o pesquisador a abranger a máxima compreensão de um problema pesquisado. A autora defende que

[...] como nenhum pesquisador tem condições para produzir um conhecimento completo da realidade, diferentes abordagens de pesquisa podem projetar luz sobre diferentes questões. É o conjunto de diferentes pontos de vista, e diferentes maneiras de coletar e analisar os dados (qualitativa e quantitativamente), que permite uma ideia mais ampla e inteligível da complexidade de um problema. (GOLDENBERG, 2004, p. 61-62).

Deste modo, a partir dos estudos desenvolvidos, das interações acerca das diferentes abordagens na produção do conhecimento em Ciências Humanas, abordagens quantitativas e qualitativas podem ser utilizadas para a compreensão desse fenômeno em estudo. Isso porque se entende que as diferentes abordagens podem complementarse nas buscas investigativas, no intuito de compreender o tema em estudo a partir de diferenciados olhares e perspectivas.

\section{A pesquisa em educação: abordagens e características}

A complementariedade entre os métodos de pesquisa, qualitativos e quantitativos, é entendida como uma das saídas possíveis diante da premissa da falta de rigor científico nas pesquisas em educação de abordagem qualitativa. A falta de descrição clara dos caminhos investigativos e elementos relacionados à postura/personalidade do pesquisador, nas diferentes fases da investigação, que podem influenciar a coleta e a análise dos dados, são corriqueiramente associados à falta de rigor e de cientificidade das pesquisas qualitativas. O papel do pesquisador na área educacional e a validade científica das pesquisas desenvolvidas são colocadas em xeque, o que se torna um agravante para a produção do conhecimento no campo de estudos em educação, diante da relevância da atividade de pesquisa para a construção do conhecimento no campo; e para a concretização da função social dos programas de pósgraduação das universidades brasileiras.

$\mathrm{Na}$ falta do rigor necessário, nas pesquisas qualitativas, um problema que pode surgir na coleta e análise dos dados é a contaminação desses pela personalidade e 
valores do pesquisador, que não prevê o necessário distanciamento dos sujeitos e dos objetos de pesquisa com os quais se aproxima na realização da investigação. $O$ necessário distanciamento do pesquisador em relação ao objeto de estudo é essencial para que não se naturalize o que deveria lhe ser estranho, a fim de abstrair análises coerentes à realidade estudada.

Quanto maior o envolvimento do pesquisador com os sujeitos e objetos de sua pesquisa, maior deve ser o seu distanciamento a fim de não contaminar suas análises a partir do vivido no lócus da pesquisa. Sobre esse distanciamento, poderíamos fazer referência à necessária objetividade que o pesquisador precisa desenvolver em sua imersão no campo de pesquisa, de acordo com a perspectiva positivista. Essa crença, da necessária separação entre pesquisador e objeto pesquisado, está associada à garantia da objetividade desejada e de uma possível neutralidade, em que o pesquisador teria diante de si a realidade evidente, o conhecimento "verdadeiro", sem influência da sua subjetividade ou de (pré) conceitos (LÜDKE; ANDRÉ, 2012).

Além do necessário distanciamento que deve tomar o pesquisador, justamente porque é entendido que para a realização da análise é preciso que o pesquisador não seja e não pense como um "nativo" do lócus da pesquisa, é importante que este tenha consciência da sua interferência na coleta de dados durante a pesquisa, como também no momento da análise desses, tendo em vista suas ideias pré-concebidas acerca dos elementos da pesquisa. Essa interferência pode ocorrer numa simples entrevista, em que o pesquisador, talvez desavisado, mantém uma postura pouco ouvinte de seu entrevistado, interpelando-o e tentando convencê-lo a partir de suas hipóteses de pesquisa e aparentes certezas.

Nesta direção, é salutar compreender que esse distanciamento não está aliado a uma ideia de neutralidade científica, em que o pesquisador deve envolver-se na atividade de pesquisa com completa objetividade, sem seus princípios e pressuposições, pois suas escolhas teórico-políticas já estão imbricadas à pesquisa, em suas diferentes etapas - desde a tomada de decisão sobre seus caminhos metodológicos à atividade de análise dos dados. Para Bogdan e Biklen (1994), diante da importância do significado para a abordagem qualitativa, os pesquisadores qualitativos mantém uma postura indagadora em relação aos sujeitos da pesquisa a fim de compreender a forma como esses vivenciam e compreendem os seus contextos e experiências. Em um exercício de diálogo, que não pode ser feito de forma neutra, os pesquisadores buscam compreender os significados sobre as experiências e contextos, a partir do ponto de vista do outro. 
Os investigadores qualitativos estabelecem estratégias e procedimentos que lhes permitem tomar em consideração as experiências do ponto de vista do informador. $O$ processo de condução de investigação qualitativa reflecte uma espécie de diálogo entre os investigadores e os respectivos sujeitos, dado estes não serem abordados por aqueles de uma forma neutra" (BOGDAN; BIKLEN, 1994, p. 51).

Outro problema, aliado às pesquisas qualitativas em educação, refere-se à análise do pesquisador influenciada por suas intuições e ideias prévias acerca do tema estudado. Esse comportamento intuitivo do pesquisador que desconsidera um quadro teórico de análise, para pensar a articulação entre a teoria base do estudo e os dados da pesquisa, coloca em risco a qualidade do trabalho a ser apresentado. A falta do rigor científico, embasado em um quadro teórico para análise dos dados, pode influenciar na produção do trabalho final, este que pode apresentar elementos como respostas que não precisariam de uma pesquisa para serem concluídas.

Assim como esses, outro problema das pesquisas em educação, citado por Goldenberg (2004) em seu livro "A arte de pesquisar: como fazer pesquisas em ciências sociais", é a justaposição entre o referencial teórico e os dados coletados na pesquisa. Segundo a autora, há dificuldades por parte dos pesquisadores em articular a teoria base do estudo com os elementos coletados, configurando os relatórios de pesquisa como uma justaposição entre teoria e dados da pesquisa. Isso porque a pesquisa, conforme Mori (2011)

[...] se concretiza na urdidura do texto. Produzir a trama final é complicado. Escrever é duro como quebrar rochas, como disse uma das grandes escritoras brasileiras, mas é também um processo fascinante, pois '[...] voam faíscas como aços espelhados' (LISPECTOR, 1984, p. 25). (MORI, 2011, p.38).

A organicidade do relatório final também é defendida como fundamental por Nosella (2010), com um instrumento necessário para revigorar e fortalecer a construção do conhecimento no campo de estudos em que se situa o pesquisador. Segundo ele, o texto final

[...] trata-se de uma obra (o relatório final) que não é uma construção arbitrária, menos ainda uma mentira, pois tem as fontes como base. Tampouco é uma reprodução mecânica de algo que está fora dele. É uma obra de cultura enraizada, de um lado, em fontes e valores alheios; de outro, em valores pessoais, em defesa de um próprio projeto social. (NOSELLA, 2010, p.181). 
Sobre a relevância da apresentação clara das pesquisas para contribuir com o fortalecimento do campo científico e com a comunicação da pesquisa à sociedade de forma geral, Nosella (2010), no artigo intitulado "Pesquisa em educação: um balanço da produção dos programas de pós-graduação", faz apontamentos acerca dos desafios da atividade de pesquisa no país. Além da necessidade de "revigorar a teoria" e fortalecer a construção do conhecimento no campo, o autor destaca a necessidade de "melhorar as narrativas" dos textos conclusivos, a partir de um "talento científico e literário" dos seus autores. Para o autor, esses devem ter uma escrita "literária" além de "elementos científicos e técnicos" a fim de ser objeto de leitura claro e conciso, disponível para o maior número de pessoas possível. O autor, nessa perspectiva, aponta que "[...] o senso comum acadêmico separa em demasia o rigor científico da forma literária; esta parece até prejudicar aquela. Tal desconsideração da forma literária, de fato, esbarra na endêmica incapacidade de escrever bem" (NOSELLA, 2010, p.181).

O cuidado com a escrita científica, com o objetivo de tornar disponível o conhecimento produzido a partir da pesquisa para o maior número de pessoas possível, está relacionado com a contribuição da pesquisa para a sociedade e para o campo científico em que se situa. Os resultados de uma pesquisa devem fazer contribuições novas, ou complementares de outro estudo, em um campo científico, e não reproduzir/repetir algo já feito, tendo em vista a necessária originalidade e ineditismo dos estudos e investigações para a construção do conhecimento no campo científico. Diante dessa necessidade, é de extrema pertinência o estudo do "estado do conhecimento" ou "estado da arte" do tema pesquisado, que fornece ao pesquisador uma visão geral acerca das pesquisas já realizadas sobre o objeto investigado.

Esse levantamento acerca dos trabalhos desenvolvidos acerca do tema de pesquisa auxilia o pesquisador a fazer uma leitura acerca da realidade do campo de estudo em que se situa, conhecendo o que já foi realizado no campo de estudo e o que ainda precisa ser feito em nível de investigações e estudos. A realização do estado do conhecimento, ou estado da arte, tem o objetivo de mostrar ao pesquisador elementos dignos e necessários para a realização da pesquisa, diante do tema estudado, confirmando ou refutando suas hipóteses sobre a pertinência do objeto de estudo escolhido - contribuindo dessa forma para o fortalecimento e desenvolvimento das pesquisas acerca do tema em estudo.

Dessa forma, o pesquisador, além de contribuir com o campo em que se situa, ao conhecê-lo, tem condições de propor estudos futuros que efetivamente contribuam 
com a validade das pesquisas de outros pesquisadores. Sobre o estado de conhecimento, Morosini e Fernandes (2014, p. 161) discutem que

[...] sua contribuição é ímpar porque nos dá uma visão do que já foi/está sendo produzido em relação ao objeto de estudo que selecionamos como tema de pesquisa; disso decorre que é possível construir uma avaliação do grau de relevância e da pertinência do tema inicialmente selecionado situando-o em um campo de produção de conhecimento.

Na discussão acerca das características das pesquisas, André (2001) faz alguns apontamentos acerca da questão das qualidades essenciais de uma boa pesquisa. A autora referencia as novas propostas e novos modelos de conceber e realizar as pesquisas que produzem novos critérios de julgamento dos novos tipos de estudo. Dentre essas mudanças, André (2001) pontua que “[...] para substituir a validade surge a plausibilidade, no lugar da fidedignidade aparece a credibilidade, e em vez de generalização fala-se em transferência [...]" (p.58). São novos critérios e formas de entender as qualidades de uma boa pesquisa, que, de acordo com a autora, devem ser gerais a todos os tipos de pesquisa e específicas dependendo do tipo da pesquisa. Critérios que devem, de acordo com André (2001), ser construídos de “forma coletiva e de longo prazo" (ANDRÉ, 2001, p. 58).

$\mathrm{Na}$ busca de compreender essas diferentes questões de pesquisa e seus contextos, a pesquisa em educação é composta por diferentes áreas do conhecimento e perspectivas de análise que cruzam seus saberes diante dos objetos em estudo. Por isso, a natureza da pesquisa em educação é pluridisciplinar e não há, de acordo com Charlot (2006), uma pesquisa dita educacional, mas sim um conjunto de áreas do conhecimento voltadas ao estudo da educação. Para o autor,

Essas pessoas trabalham juntas, nos mesmos ambientes - os departamentos de educação -, pesquisam nas mesmas estruturas da pós-graduação, mas isso não quer dizer que existe uma disciplina, um campo de pesquisa específico chamado educação ou ciências da educação. As ciências da educação possuem uma realidade institucional, administrativa, organizacional, mas não têm existência epistemológica específica. (CHARLOT, 2006, p. 8).

Nesse sentido, entende-se que a pesquisa em educação não pode limitar-se à simples coleta de dados a partir de um determinado conjunto de técnicas e métodos. Esta que, por vezes, pode encaminhar-se para análises superficiais e generalistas sobre a pesquisa - sem a necessária reflexão crítica acerca de que todo método de pesquisa está 
fundamentado em uma teoria da ciência e esta, por sua vez, aliada a uma teoria do conhecimento. A escolha metodológica do pesquisador deve ser realizada após este definir qual o seu objeto de pesquisa. Essa premissa defende que o método deve ser pertinente à busca sobre determinado objeto e não que este deve ser interessante àquele. Sánchez Gamboa (2012), nesse sentido, considera que

[...] importante assinalar que o método ou modo, ou caminho, de se chegar ao objeto, o tipo de processo para chegar a ele, é dado pelo tipo de objeto e não o contrário, como pode ser entendido quando o caminho ganha destaque, dado o êxito de certos métodos em certos campos, chegando a ser priorizado de tal maneira que o objeto fica descaracterizado ("desnaturalizado"), recortado ou enquadrado nos códigos restritos das metodologias. (SÁNCHEZ GAMBOA, 2012, p. 28).

Essa discussão acerca dos critérios que definem o que é uma boa pesquisa em educação está relacionada às formas de avaliação desenvolvidas pela Coordenação de Aperfeiçoamento do Pessoal de Nível Superior (CAPES), pelo Conselho Nacional de Desenvolvimento Científico e Tecnológico (CNPq) e pela Fundação de Amparo à Pesquisa (Fapesp), quando estas avaliam as dissertações e teses dos programas de pósgraduação em educação. Dentre os critérios atualmente considerados estão a relevância social das pesquisas, a definição clara dos seus objetos de análise, e a contribuição destes estudos para o avanço da produção do conhecimento no campo (ANDRÉ, 2001).

Nessa discussão, Nosella (2010) aponta a necessidade de uma revisão das formas de avaliação desenvolvidas sobre a atividade de pesquisa nos programas de pósgraduação, propondo uma crescente descentralização, em que haja menos burocracias e regras a priori - em processos avaliativos que considerem a relevância da interação social e da avaliação posteriori de eventos e atividades. Para o autor (2010), “[...] tratase de criar um sistema de avaliação que articule de forma equilibrada a centralização com a regionalização e normas estabelecidas a priori com verificações feitas a posteriori" (p. 182).

\section{Considerações finais}

A atividade de pesquisa em educação exige um estudo aprofundado para aqueles que desejam construir um projeto de pesquisa pertinente ao campo de estudos em que se situa. O compromisso social dos pesquisadores dos programas de pós-graduação em educação está relacionado ao compromisso social das instituições de ensino superior 
pela produção do conhecimento e pela necessária contribuição desta com os sistemas de ensino, e com os processos de formação de professores. Em um estudo sobre a constituição do campo de estudos sobre os processos de formação de professores, Marli André (2010) discute o necessário rigor que deve pautar as pesquisas voltadas à formação de professores e a importância de apresentarem suas pesquisas de forma clara à comunidade científica.

O campo de pesquisa sobre a formação de professores vem se constituindo como um espaço fortalecido pelos interesses dos pesquisadores por questões referentes aos processos de formação de professores, inicial e continuada, e por questões relacionadas a esses processos. É um campo de investigação que se constitui com fundamental importância, pois é entendido como um objeto e um instrumento de transformação dos processos formativos, escolares e universitários. Há um interesse crescente em compreender os contextos de trabalho, as condições de carreiras profissionais, salários e valorização social da profissão docente, as trajetórias de vida de professores, os saberes e as práticas docentes, os níveis de autonomia e de participação nas tomadas de decisões nos espaços de trabalho.

André (2010), ao se referir ao campo de pesquisa em educação, especialmente sobre a formação de professores, afirma que é preciso que as pesquisas na área tenham uma postura indagante não só acerca do que pensam, fazem e sentem os professores, mas que busquem compreender em que contextos e condições essas formas de pensar, fazer e sentir estão sendo produzidas, para que efetivamente haja avanços significativos no campo de pesquisas na área educacional. Para a autora, os estudos em educação “[...] só assim poderão ser compreendidos e reconhecidos socialmente. A pesquisa poderá, sim, contribuir para a valorização social do campo, se for desenvolvida com todo rigor científico, deixando evidentes suas contribuições” (ANDRÉ, 2010, p. 179). A autora afirma que o propósito de realizar análises mais contundentes, superando o senso comum e crenças equivocadas, numa perspectiva de trabalho colaborativo entre professores das universidades e das escolas, baseia-se na "[...] intenção de descobrir os caminhos mais efetivos para alcançar um ensino de qualidade, que se reverta numa aprendizagem significativa para os alunos" (ANDRÉ, 2010, p. 176).

Olhar para as produções que estão sendo feitas e perceber se elas visam manter o status quo ou se estão voltadas para a transformação das realidades é um tema interessante de investigação para perceber o caráter das pesquisas em educação. A qual projeto societário essas pesquisas estão comprometidas? Qual rigorosidade científica 
embasa as produções feitas? É preciso olhar para os processos investigativos nas ciências humanas e sociais, e especialmente às voltadas à educação, para compreender seus processos e analisar o que vem sendo produzido na área, tendo em vista a validade dessas produções, como "[...] uma tarefa coletiva e de longo prazo, que precisa envolver todos aqueles que de alguma forma se preocupam com o desenvolvimento e com os resultados das pesquisas na área da educação" (ANDRÉ, 2001, p.52). Para a autora (2005), a qualidade dos processos investigativos em educação deve ser discutida de forma coletiva, tendo em vista a discussão para além dos programas de pós-graduação das universidades brasileiras, envolvendo outras instituições e entidades ligadas à atividade de pesquisa no país. Segundo André (2005), é

[...] preciso promover o debate nas universidades, nas escolas, nas agências de fomento, nas revistas, na Internet de modo a criar condições para que possam emergir concepções consensuais do que seja uma "boa" ou uma "má" pesquisa. (ANDRÉ, 2005, p. 1).

Estudar as abordagens de pesquisa em educação é uma atividade que deve ser contínua nos cursos de pós-graduação e nos espaços que a realizam. Isso porque o estudo sobre metodologias de pesquisa não está associado apenas a formas de realizar as pesquisas, mas também a perspectivas de análise que podem, a partir da construção do conhecimento, contribuir para fazer a manutenção da condição social em que vivemos ou para transformá-la. As disciplinas sobre metodologias de pesquisa, deste modo, tratam além de técnicas e métodos que envolvem regras para fazer pesquisas - tratam de formas de compreensão das realidades individuais e sociais, auxiliam na reflexão e problematização sobre o(s) mundo(s).

Talvez, como já sinalizado por André (2001), as questões que norteiam as discussões sobre a pesquisa qualitativa voltada à educação devem ser estudadas e pautadas como objetos de luta coletiva para a "[...] melhoria das condições de produção do trabalho científico" (p. 63), comprometidas com a busca pelo rigor nas pesquisas em educação e pela transformação das realidades - educacionais, sociais e econômicas.

\section{REFERÊNCIAS}

ANDRÉ, M. E. D. A. Pesquisa em educação: buscando rigor e qualidade. Cadernos de Pesquisa, n. 113, p. 51-64, 2001. Disponível em:

<http://nead.uesc.br/arquivos/Biologia/modulo_7_bloco_1/tcc/texto_2_pesquisa_em_ed ucacao_buscando_rigor_e_qualidade.pdf>. Acesso em: 05 jan. 2017. 
ANDRÉ, M. E. D. A. Pesquisa em educação: questões de teoria e método. Revista Educação e Tecnologia, CEFET/MG, Belo Horizonte, v. 10, n.1, p. 29-35, 2005. Disponível em: <https://seer.dppg.cefetmg.br/index.php/revista-et/article/view/72>. Acesso em: 05 jan. 2017.

ANDRÉ, M. E. D. A. Formação de professores: a constituição de um campo de estudos. Revista Educação, v. 33, n. 3, p. 174-181, 2010. Disponível em:

<http://revistaseletronicas.pucrs.br/fefid/ojs/index.php/faced/article/view/8075>. Acesso em: 05 mar. 2017.

ANDRÉ, M. E. D. A. O que é um estudo de caso qualitativo em educação? Revista da FAEEBA - Educação e Contemporaneidade, Salvador, v. 22, n. 40, p. 95-103, 2013. Disponível em: <https://www.revistas.uneb.br/index.php/faeeba/article/view/753.> Acesso em: 10 mar. 2017.

BOGDAN, R.; BIKLEN, S. Investigação qualitativa em educação: uma introdução à teoria e aos métodos. Tradução: Maria João Alvarez, Sara Bahia dos Santos e Telmo Mourinho Baptista. Portugal, Porto: Editora Porto, 1994. 336p.

CHARLOT, B. A pesquisa educacional entre conhecimentos, políticas e práticas: especificidades e desafios de uma área de saber. Revista Brasileira de Educação, v. 11 n. 31, p. 7-18, 2006. Disponível em: <http://www.scielo.br/scielo.php?pid=S1413$24782006000100002 \&$ script=sci_abstract\&tlng=pt $>$ Acesso em: 10 mar. 2017.

DEVECHI, C. P. V.; TREVISAN, A. L. Sobre a proximidade do senso comum das pesquisas qualitativas em educação: positividade ou simples decadência? Revista Brasileira de Educação, v. 15, n. 43, p. 148-201, 2010. Disponível em: $<$ http://www.scielo.br/scielo.php?script=sci_arttext\&pid=S1413-24782010000100010>. Acesso em: 02 fev. 2017.

FREIRE, P. Criando métodos de pesquisa alternativa: aprendendo a fazê-la melhor através da ação. In: BRANDÃO, Carlos Rodrigues (Org). Pesquisa Participante. São Paulo: Brasiliense, 1981. p. 34-35.

FREIRE, P. Pedagogia da autonomia: saberes necessários à prática educativa. São Paulo: Paz e Terra, 1996.

GOLDENBERG, M. A arte de pesquisar: como fazer pesquisa em Ciências Sociais. $8^{\mathrm{a}}$ ed. Rio de Janeiro: Record, 2004.

LÜDKE, M.; ANDRÉ, M. E. D. A. Pesquisa em educação: abordagens qualitativas. São Paulo: E.P.U., 2012.

MARCONI, M. de A.; LAKATOS, E. M. Fundamentos de Metodologia Científica. $5^{\text {a }}$ ed. São Paulo: Editora Atlas S. A., 2003.

MORI, N. N. R. Metodologia da Pesquisa. Maringá: Eduem, 2011. 
MOROSINI, M. C.; FERNANDES, C. M. B. Estado do conhecimento: conceitos, finalidades e interlocuções. Educação Por Escrito, v.5, n. 2, p. 154-164, 2014.

Disponível em:

<http://revistaseletronicas.pucrs.br/ojs/index.php/porescrito/article/view/18875>.

Acesso em: 05 mar. 2017.

NOSELLA, P. A pesquisa em educação: um balanço da produção dos programas de pós-graduação. Revista Brasileira de Educação, v.15, n.43, p. 177-203, 2010.

Disponível em: <http://www.scielo.br/pdf/rbedu/v15n43/a13v15n43.pdf>. Acesso em: 10 mar. 2017.

SÁNCHEZ GAMBOA, S. Pesquisa em educação: métodos e epistemologias. $2^{\text {a }}$ ed. Chapecó: Argos, 2012.

SAVIANI, D. Educação: do senso comum à consciência filosófica. $18^{\mathrm{a}}$ ed. Campinas, São Paulo: Autores Associados, 2009.

\section{Como referenciar este artigo}

THESING, Mariana Luzia Corrêa.; COSTAS, Fabiane Adela Tonetto. A pesquisa em educação: aproximações iniciais. Revista Ibero-Americana de Estudos em Educação, Araraquara, v. 12, n. 3, p. 1839-1853, jul-set/2017. Disponível em: <http://dx.doi.org/10.21723/riaee.v12.n.3.2017.9644>. E-ISSN: 1982-5587.

Submetido em: 03/04/2017

Aprovação final em: 02/07/2017 